\title{
THE EFFECT OF “ARM ACTIVATION" BRAIN EXERCISE ON FINE MOTORIC DEVELOPMENT IN PRESCHOOL CHILDREN IN LAMONGAN, EAST JAVA
}

\author{
Atiul Impartina \\ School of Health Sciences Muhammadiyah, Lamongan, East Java
}

\begin{abstract}
Background: Fine motor skills play an important role in a child's development and educational achievement. Fine motor skills are essential for performing everyday skills like self care tasks (e.g. clothing fastenings, opening lunch boxes, cleaning teeth, using cutlery) and academic skills (e.g. pencil skills of drawing, writing and colouring, as well as cutting and pasting). Without the ability to complete these every day tasks, a child's self esteem can suffer and their academic performance is compromised. They may also be unable to develop appropriate independence in life skills (such as getting dressed and feeding themselves). This study aimed to investigate the effect of "arm activation" brain exercise on fine motoric development in preschool children in Lamongan, East Java.
\end{abstract}

Subjects and Method: This was a quasi experimental study with one group pre and post design. The study was conducted at Hidayatullah preschool children, Ganggang, Ngimbang, Lamongan, East Java. A sample of 29 preschool children was selected for this study by total sampling. The dependent variable was fine motoric development. The independent variable was "arm activation" brain exercise. The fine motoric development was measured by Denver development screening test (DDST). The data were analyzed by Wilcoxon.

Results: Fine motor development score after arm activation exercise (mean= $2.89, \mathrm{SD}=0.41)$ was higher than before arm activation exercise (mean= 2.52; $\mathrm{SD}=$ 0.57) with $\mathrm{p}=0.001$.

Conclusion: Arm activation exercise is effective to improve fine motor development in preschool children.

Keywords: arm activation exercise, fine motoric development, preschool children

\section{Correspondence:}

Atiul Impartina. School of Health Sciences Muhammadiyah Lamongan, East Java. Email: atiulimpartina16@gmail.com. Mobile: 081553701055. 